\title{
O uso da fotografia como recurso emancipador: um relato de experiência com pessoas em situaçáo de rua
}

\author{
Juliana de Oliveira Perez, Regina Célia Fiorati, Leonardo Martins Kebbe, \\ Beatriz Cardoso Lobato
}

Curso de Terapia Ocupacional, Faculdade de Medicina de Ribeirão Preto, Universidade de São Paulo - USP, Ribeirão Preto, SP, Brasil

\begin{abstract}
Resumo: Este trabalho tem como objetivo apresentar uma reflexão acerca da experiência do uso da fotografia pelo terapeuta ocupacional junto a pessoas em situação de rua de um Centro de Referência Especializado de Assistência Social para Pessoas em Situação de Rua (CREAS-POP) de um município do interior de São Paulo. A Oficina de fotografia objetivou proporcionar à pessoa em situação de rua uma inserção e relação diferenciada com o espaço urbano e com a população. Os participantes foram convidados a fotografar algo que lhes despertasse interesse nos espaços urbanos. A fotografia proporcionou a eles uma visão diferente deles mesmos, ao permitir que se percebessem como sujeitos de direitos e atores sociais e não mais como objeto de observação da sociedade. Ao se perceberem como cidadãos, saíram da invisibilidade, observando-se melhora na autoestima e maior engajamento nas atividades propostas. A oficina resultou também em uma exposição fotográfica aberta à população, a qual objetivou interferir nas preconcepções e preconceitos que a sociedade construiu a respeito da pessoa em situação de rua e dar visibilidade para o potencial criativo dessa população.
\end{abstract}

Palavras-chave: Terapia Ocupacional, Pobreza, Condições Sociais, Marginalização Social.

\section{The use of photography as emancipatory action: an experience report with people in street situation}

\begin{abstract}
This study aims to present a reflection on the experience of the use of photography by the occupational therapist with the people living in the streets of a Specialized Reference Center for Social Assistance to People in Street Situation - CREAS-POP of a municipality in Sao Paulo state, Brazil. The Photography Workshop aimed to provide an insertion and a different relationship with the urban space and population to the person living in the streets. Participants were asked to photograph something that arouses their interest in urban spaces. The photograph gave them a different view of themselves, allowing them to perceive themselves as subjects with rights and social actors, and not as an object of societal observation. Perceiving themselves as citizens, they came out of invisibility, and an improvement in self-esteem and greater engagement in the activities proposed was observed. The workshop also resulted in a photo exhibit open to the public that aimed to interfere with pre-conceptions and prejudices that society has built about people in street situation and give visibility to the creative potential of this population.
\end{abstract}

Keywords: Occupational Therapy, Poverty, Social Conditions, Social Marginalization.

Autor para correspondência: Regina Célia Fioratti, Universidade de São Paulo, Divisão de Terapia Ocupacional. Av. Bandeirantes, 3900 , Bairro Monte Alegre, CEP 14049-900, Ribeirão Preto, SP, Brasil, e-mail: reginacf@ fmrp.usp.br

Recebido em 28/9/2013; Revisão em 8/3/2014; Aceito em 4/5/2014. 


\section{Introdução}

O objetivo deste trabalho é apresentar uma reflexão acerca da experiência do uso da fotografia pelo terapeuta ocupacional junto a pessoas em situaçáo de rua no Centro de Referência Especializado de Assistência Social para Pessoas em Situação de Rua (CREAS-POP) de um município do interior de São Paulo. Essa reflexão desenvolveu-se com base nas atividades do Estágio Profissionalizante em Terapia Ocupacional do Curso de Terapia Ocupacional da Faculdade de Medicina de Ribeirão Preto, Universidade de São Paulo (TO-FMRPUSP).

O CREAS-POP é um serviço socioassistencial que compóe o Sistema Único de Assistência Social (SUAS), recomendado aos municípios com mais de 250 mil habitantes. Esse serviço deve oferecer atenção especializada a pessoas em situação de rua, promovendo atendimento e atividades para o desenvolvimento de sociabilidade, fortalecimento de vínculos interpessoais e/ou familiares e construção de novos projetos de vida. O CREAS-POP deve ofertar espaços destinados à realização de atividades coletivas, higiene pessoal, alimentação e espaço para guarda de pertences pessoais, além de atendimento psicossocial, ficando a cargo de cada município a implantação desse serviço (BRASIL, 2010).

O CREAS-POP oferece assistência diurna diária, funcionando em rede com outros serviços de assistência social do município, governamentais ou não, visando o fortalecimento de vínculos e a reinserção dessa pessoa na sociedade. Tem atuação voltada a três eixos principais: garantia dos direitos, resgate da autoestima e reorganização dos projetos de vida (RIBEIRÃO..., 2011).

A população em situação de rua é caracterizada por sua condição de pobreza extrema, pela interrupçáo ou fragilidade de vínculos familiares e pela falta de moradia convencional regular, e, portanto, é forçada a habitar lugares públicos (ruas, praças, cemitérios), áreas degradadas (galpóes e prédios abandonados, ruínas) e, ocasionalmente, utilizam abrigos e albergues para pernoitar (BRASIL, 2009).

De acordo com a Pesquisa Nacional sobre a População em Situação de Rua, essa população é predominantemente masculina $(82 \%)$ e mais da metade (53\%) está em idade economicamente produtiva, com idade entre 25 a 44 anos, apresentando como razões para viverem na rua os problemas de alcoolismo e/ou drogas (35,5\%), o desemprego (29,8\%) e as desavenças com pai/mãe/irmãos $(29,1 \%)$ (BRASIL, 2008).
Essa população apresenta níveis de renda baixos, nos quais a maioria $(52,6 \%)$ recebe entre $\mathrm{R} \$ 20,00 \mathrm{e}$ $\mathrm{R} \$ 80,00$ semanais. Dentre as atividades realizadas destacam-se: catador de materiais recicláveis $(27,5 \%)$, flanelinha (14,1\%), construção civil $(6,3 \%)$, limpeza $(4,2 \%)$ e carregador/estivador $(3,1 \%)$, sendo que $15,7 \%$ das pessoas entrevistadas relataram pedirem dinheiro como principal meio para a sobrevivência. Esses dados sáo importantes para desmistificar o fato de que a população em situação de rua é composta por "mendigos" e "pedintes", pois aqueles que pedem dinheiro para sobreviver constituem minoria (BRASIL, 2008).

A condição de rua, vivenciada por um número crescente de pessoas nas regióes urbanas, é de extrema relevância na composição da pobreza nas sociedades capitalistas. A análise das condições histórico-estruturais que deram origem a população em situaçáo de rua remontam ao fenômeno da pauperização vivenciado por países da Europa Ocidental no período pré-industrial (SILVA, 2009).

Entretanto, o aumento sensível do número de pessoas em exclusão social é percebido principalmente em decorrência da crise do modelo social, econômico e político dos Estados de Bem-Estar Social, a partir da década de 1950, nos países europeus. O Estado de Bem-Estar Social, que delegava ao Estado a responsabilidade de elaborar, organizar e desenvolver aspectos sociais, políticos e econômicos visando atender às necessidades da população, cede espaço para uma orientação de gestão política e econômica neoliberais. O papel do Estado, nesse modelo, é gerir os recursos da nação, não se responsabilizando pelo desenvolvimento de açôes e serviços, ficando a sociedade e seus diferentes atores responsáveis por organizar-se e prover a assistência necessária. Dessa forma, com o neoliberalismo, a seguridade social deixa de ser tarefa do Estado, o que compromete o vínculo social, aspecto que se agrava com a transformação das relaçôes entre a economia e sociedade, decorrentes da crise do sistema produtivo capitalista e dos modos de constituiçáo das identidades individuais e coletivas (SAWAIA, 2007).

No Brasil, o fenômeno tem origem no processo de industrialização, que substituiu o modelo de acumulação agroexportadora, vigente no período de 1930 a 1980 e que marcou definitivamente a economia e vida do país (SILVA, 2009).

A exclusão social, portanto, tem origem econômica, social, cultural e política e caracteriza-se, também, pela falta de pertencimento social, falta de perspectivas, dificuldade de acesso à informaçáo e perda de autoestima. Acarreta consequências na saúde geral das pessoas, em especial a saúde mental, 
relaciona-se, frequentemente, com o mundo do crime organizado, principalmente do tráfico de drogas, relativiza valores e estabelece padróes e perspectivas de emancipação sociais muito restritas (COSTA, 2005). A perda de vínculos familiares, decorrente do desemprego, da violência, da perda de algum ente querido, perda de autoestima, alcoolismo, drogadição, doença mental, entre outros fatores, são alguns dos principais motivos que levam as pessoas a habitarem e, às vezes, morrerem nas ruas (BULLA; MENDES; PRATES, 2004).

As questôes referentes à situação de exclusão e vulnerabilidade social também integram o campo de conhecimento e prática da Terapia Ocupacional (TO). A Terapia Ocupacional Social começou a ser discutida na década de 1970 , justamente no momento em que ocorriam movimentos sociais. Nesse momento, em que o Brasil encontrava-se sob o regime militar, começou a incorporação da profissáo dentro das instituiçôes totais, como presídios e FEBEM (Fundação Estadual do Bem-Estar do Menor). Nessas instituiçôes, os terapeutas ocupacionais exerciam um papel de "promotores de adaptação social". $\mathrm{Na}$ década de 1980, iniciaram-se relevantes debates sobre o processo de desinstitucionalização, principalmente dentro do campo da saúde mental. Com essa proposta de desinstitucionalização, aliada às intervençôes no âmbito territorial, foi necessário repensar a prática profissional e inserir o conceito de cidadania na prática e no campo de conhecimentos da Terapia Ocupacional. Foi a partir dessas transformaçóes que esse profissional começou a ampliar suas açóes para o território e comunidades, levando em consideração a constituição histórica e as relaçôes socioeconômicas e culturais desenvolvidas (BARROS; GUIRARDI; LOPES, 2002; BARROS; LOPES; GALHEIGO, 2007; GALHEIGO, 1997; OLIVER; BARROS, 1999).

Essa intervenção tem como metas a construção de novas possibilidades de existência e a efetivação e garantia de direitos a bens e serviços disponíveis na sociedade. Dessa forma, desenvolve-se uma Terapia Ocupacional com o objetivo de transformar a atuação anterior e construir metodologias e tecnologias para trabalhar junto a esses grupos, de forma a buscar a criaçáo e o fortalecimento de redes sociais de suporte, emancipação e autonomia político-social dessas populaçóes. Com essa proposta, constitui-se a Terapia Ocupacional no campo social, com novos elementos que a distinguem da atuação voltada para as populações institucionalizadas (DRUMMOND, 2007).

Portanto, no campo social, o terapeuta ocupacional desenvolve seu trabalho para além do indivíduo e instituição, assumindo papel de articulador social frente à complexa realidade social apresentada pelos sujeitos atendidos. Enquanto articulador social, esse profissional precisa conhecer os recursos sociais disponíveis e as formas de acessá-los, bem como as políticas públicas e os direitos da população atendida, no intuito de articular os recursos existentes na atenção às necessidades da população. Assim a intervenção do terapeuta ocupacional necessita abranger açóes que permitam a discussão das políticas públicas existentes e a participação na elaboração de garantias legais dos direitos das populaçóes em situação de vulnerabilidade social. $\mathrm{Na}$ sua atuação, esse profissional estabelece um diálogo entre a microestrutura - seu cotidiano de açōes com sua populaçáo alvo - e a macroestrutura - no que diz respeito às políticas sociais -, articulando uma política que viabilize à essa populaçáo o acesso aos seus direitos (MALFITANO, 2005).

Nessa perspectiva, terapeutas ocupacionais no campo social têm realizado estudos e desenvolvido intervenções abrangendo pessoas em situação de rua (ALMEIDA et al., 2011; GHIRARDI et al., 2005; LOPES; PALMA; REIS, 2005; MALFITANO; MARQUES, 2011)

O Curso de Graduação em Terapia Ocupacional da Faculdade de Medicina da Universidade de Sáo Paulo (TO-FMRPUSP) iniciou suas açóes junto à população em situação de rua em 2011, em parceria com o Centro de Referência Especializado da Assistência Social para a População em Situação de Rua (CREAS-POP), por meio das atividades do Estágio Profissionalizante do quinto ano do curso.

O presente relato é resultado da experiência desenvolvida no Estágio Profissional em Terapia Ocupacional na Atençáo ao Adulto junto a pessoas em situação de rua em um município do interior de São Paulo. Este trabalho tem como objetivo apresentar a experiência do uso da fotografia como recurso terapêutico ocupacional no campo social e as reflexôes desse recurso como instrumento de emancipação, autovalorização e reconstituição de histórias de vida.

\section{A Oficina de Fotografia: contexto e desenvolvimento}

A inserçấo do estágio profissional em Terapia Ocupacional no CREAS-POP tinha por objetivo favorecer que os sujeitos com vivência de rua resgatassem sua cidadania e emancipação social, no intuito de constituírem-se como sujeitos de direitos e pertencentes à sociedade. Dessa forma, 
foram propostas oficinas que objetivaram criar oportunidades para a expressão criativa, a descoberta e ampliação de habilidades, tanto produtivas quanto favorecedoras de interação social, a discussão sobre os direitos relacionados à saúde, educação, seguridade social e o acesso aos recursos sociais disponíveis, no intuito de instrumentalizar as pessoas em situação de rua na construçáo de novas possibilidades de vida e inserçáo social.

As atividades do estágio profissional foram desenvolvidas com frequência de dois encontros semanais. Às terças-feiras era realizado o Grupo de Vivência em Ocupaçóes Profissionalizantes, com o objetivo de criar oportunidades para o participante experimentar, aprender, ensinar, criar e, assim, reconhecer-se como sujeito, com história, desejos, direitos, potências e fragilidades. Às sextas-feiras era desenvolvido o Grupo de Cidadania, cujo objetivo era apresentar e analisar, juntamente com os usuários do serviço, as propostas de ação referidas a grupos populacionais em processos de ruptura das redes sociais de suporte - população em situação de rua - problematizar açóes governamentais e não governamentais, na perspectiva dos direitos sociais; debater a sociedade capitalista, o papel do Estado e as açôes para o acesso aos bens sociais e aos direitos; e discutir as trajetórias dos movimentos sociais e da sociedade civil nesses campos.

Ambos os grupos eram heterogêneos e abertos e, por esse motivo, cada encontro era formado por diferentes participantes. Os grupos eram coordenados pela estagiária de Terapia Ocupacional, com supervisão dos docentes da área.

No Grupo de Vivência em Ocupações Profissionalizantes foi desenvolvida a atividade de fotografia, que passou a ser chamada Oficina de Fotografia, com início em março de 2013 e término em junho de 2013. Nessa oficina, propôs-se que os participantes fotografassem algo que lhes despertasse interesse nos espaços urbanos.

A proposta do uso da fotografia objetivou proporcionar à pessoa em situação de rua uma inserção e relação diferenciada com o espaço urbano e com a população. Compreende-se que a pessoa nessa condição faz parte do cenário social, porém a sociedade, de um modo geral, ignora-a, evita-a, com base no preconceito de que esse sujeito apresenta uma ameaça à segurança e à ordem social. Frente a essa realidade, a fotografia coloca a pessoa em situação de rua na condição de observador da dinâmica do espaço urbano, do qual faz parte, e possibilita que esse espaço seja (re)conhecido a partir da percepção das pessoas participantes da oficina, transformando-os, ao viabilizar a expressão cultural, a criação artística e a comunicação por meio da imagem, em sujeitos (BAUER, 2002).

A Oficina de Fotografia iniciou-se com a apresentação da máquina fotográfica digital ao grupo e com as orientações sobre como utilizá-la (Figura 1). Para muitos, esse foi o primeiro contato com o equipamento, sendo ele manuseado com curiosidade, por alguns, e com receio, frente ao novo, por outros. Nessa experiência, depararam-se com uma dimensão da prática social para a qual não haviam sido informados: a tecnologia. Havia apenas uma máquina disponível, que foi utilizada e compartilhada por todos os participantes. Essa aparente limitação foi revertida pela coordenadora do grupo através de uma abordagem que estimulou e favoreceu a cooperação, comunicação e a interação entre os participantes, de forma que todos pudessem manuseá-la e captar as imagens escolhidas.

Inicialmente, as atividades da oficina foram realizadas nos arredores do estabelecimento de assistência social, onde foram fotografadas ruas (Figura 2), vitrines - e, interessante observar, que alguns participantes fotografaram seu próprio reflexo

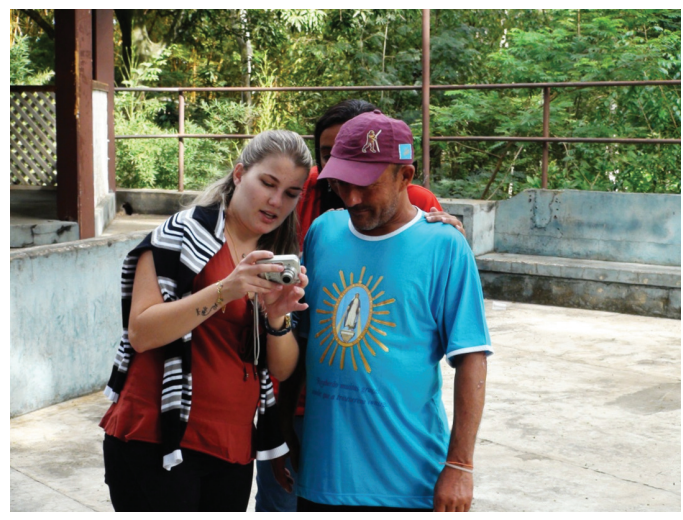

Figura 1. Explicação dada pela estagiária ao participante sobre o uso da máquina fotográfica.

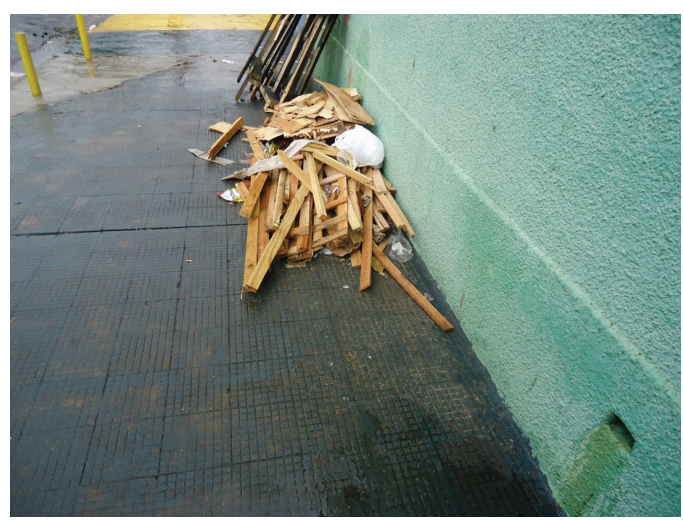

Figura 2. Rua nos arredores do CREAS-POP; fotografia feita por um dos participantes. 
a partir dos vidros das vitrines (Figura 3). Além disso, foram fotografados carros, igrejas, placas indicando o cruzamento entre ruas e as sombras deles mesmos na calçada. Nesse momento, o grupo era acompanhado pela estagiária, supervisores e uma funcionária do serviço. Cada foto realizada era seguida de comentários das pessoas participantes da oficina sobre a imagem produzida, sobre as vivências deles naquele espaço e sobre recordaçóes das histórias de vida e vivências deles em outros espaços sociais.

A atividade despertou um interesse crescente em explorar mais espaços urbanos e coletivos no grupo, dessa forma, surgiu o desejo de ir a outros lugares da cidade, que remetiam a lembranças das histórias de vida, como o Museu do Café (Figura 4), o Bosque Municipal, parques (Figura 5), praças e o Teatro Pedro II. Além desses, alguns lugares foram sugeridos pelas coordenadoras da atividade, como o Museu de Arte e outros locais culturais da cidade.

A cada início de oficina, diante da presença de novos participantes, prosseguia-se com a apresentação da máquina fotográfica, explicação sobre o seu manuseio e a saída para local escolhido pelos participantes para a realização das fotografias. Ao retornar ao CREAS-POP, os participantes eram

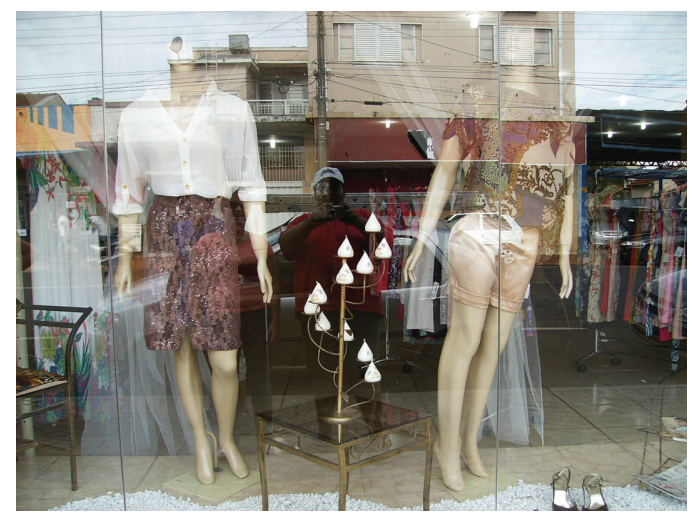

Figura 3. Fotografia da vitrine de uma loja com reflexo do próprio participante no vidro.

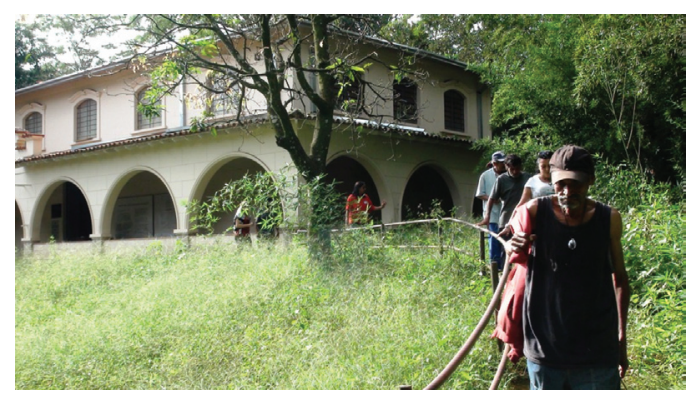

Figura 4. Visita ao Museu do Café; fotografia feita por um dos participantes. convidados a olhar as fotografias produzidas, sendo conduzidos a um processo de reflexão e descoberta de detalhes das imagens.

No início, participavam da oficina, em média, quatro a cinco usuários do serviço, porém com o desenvolvimento da atividade observou-se um aumento do interesse, mobilizando-se a participação de outros usuários que até o momento mostravam-se resistentes a participar das atividades propostas. Dessa forma, a oficina passou a contar com 14 participantes, que passaram a frequentar regularmente os encontros.

\section{O terapeuta ocupacional e} sua atuação com pessoas em
situação de rua: a fotografia
como recurso para a
construção de novos olhares e
sentidos

O recurso da fotografia permitiu que os participantes desenvolvessem um novo olhar sobre a rua e possibilitou uma (re)apropriação desse espaço, agora como atores sociais. A pessoa em situaçáo de rua tende a assumir o papel de ser objeto de observaçáo da sociedade, quando ela passa a ser aquele que observa e analisa a rua, o que foi propiciado pela oficina, muda também seu olhar sobre si mesma, vendo-se como sujeito. Além disso, ir para a rua com as terapeutas ocupacionais, sendo a intervenção fora do estabelecimento, propiciou uma mudança de "estatuto social" e, com isso, eles deixaram de se ver como "indigentes" e passaram a se perceber como cidadãos. Nota-se, com essa autopercepção deles como sujeitos de suas açóes e como criadores de cultura, uma melhora da autoestima dos participantes.

A sociedade apresenta representaçóes sociais pejorativas em relação à população em situação de rua, as quais se materializam nas relaçôes sociais. As designaçóes comuns dirigidas às pessoas em situação de rua, como "vagabundo, preguiçoso, bêbado, sujo, perigoso, coitado, mendigo", resultam em sua exclusão social e na sua sobrevivência à margem da sociedade. Os significados atribuídos ao moderador de rua, e partilhados socialmente, influenciam na construção da identidade dessas pessoas (MATTOS; FERREIRA, 2004).

O desafio está em vislumbrar como, em uma sociedade com tantas contradições insuperáveis, contrastes e exclusões, é possível criar referenciais positivos para a constituição da identidade valorativa da população que vive em situação de rua, às vezes 

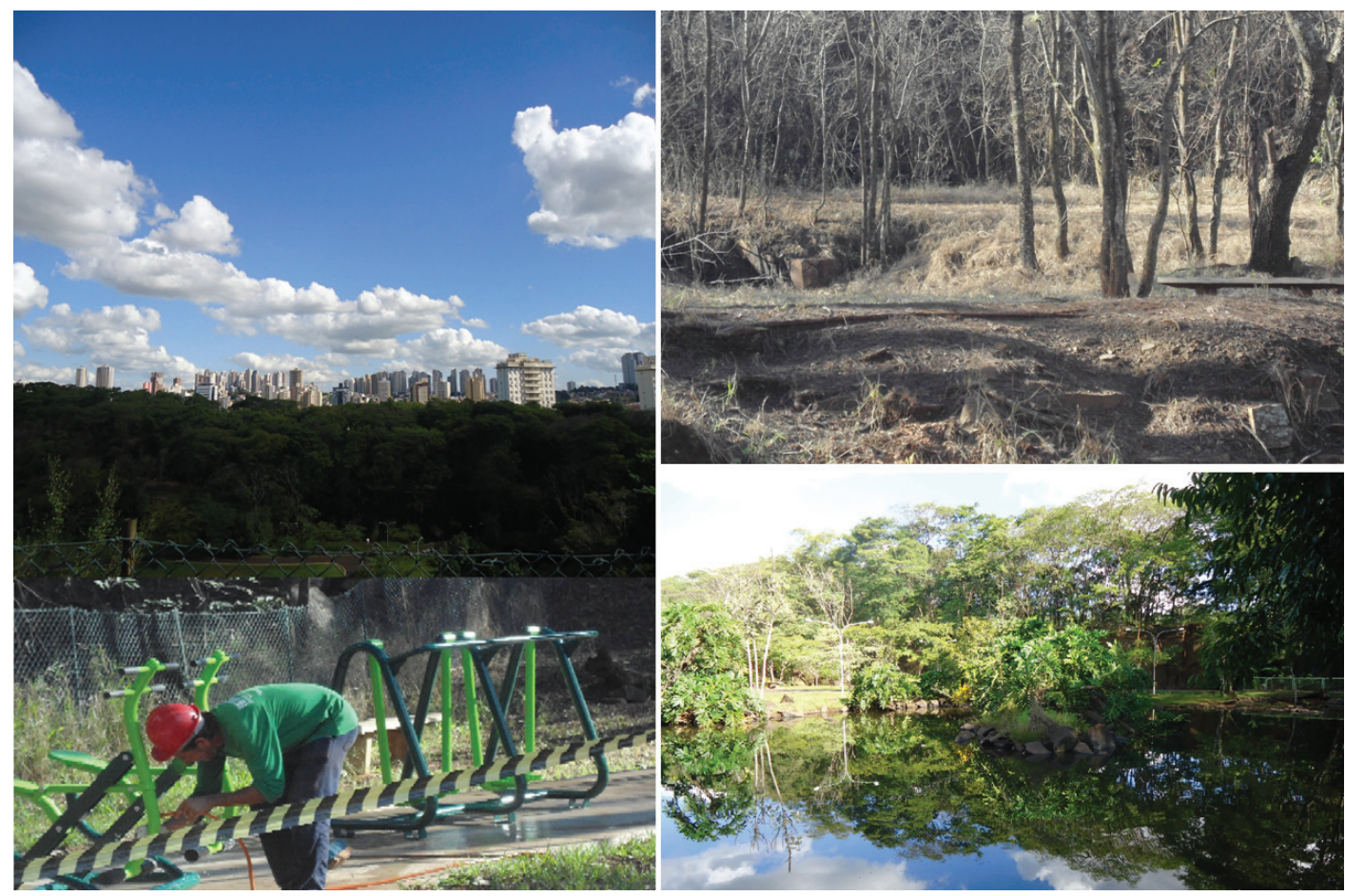

Figura 5. Fotografias dos parques da cidade feitas pelos participantes.

invisível aos olhos da sociedade formal, às vezes expressão agressiva da contradição social. Estar incluído, sentir-se pertencendo à sociedade e planejar o próprio futuro depende de uma mudança de atitude social no sentido de acolhimento (COSTA, 2005).

A representaçáo social pejorativa do morador de rua está presente no imaginário dos diversos atores sociais, mesmo daqueles que integram os diversos serviços de assistência destinados a essa população. Dessa forma, embora o CREAS-POP integre essa rede de serviços e constitua um serviço especializado de assistência à pessoa em situação de rua, não dispóe dos recursos físicos, econômicos e humanos necessários para o desenvolvimento das ações previstas por esse programa, bem como não oferece a capacitação necessária aos funcionários que irão desenvolver essas atividades junto a essa população.

Frente a essa realidade da pessoa em situação de rua, a Oficina de Fotografia possibilitou que os participantes trouxessem questôes relacionadas à sua história de vida e seus desejos, favorecendo maior interação com a estagiária e funcionários do CREAS-POP, permitindo um maior espaço de expressão e comunicação. Essa aproximação entre usuários e equipe possibilitou que alguns profissionais pudessem rever suas preconcepções e a sua forma de interação com a população atendida.
Outro desdobramento da Oficina de Fotografia foi a realização de uma exposição fotográfica intitulada AndaraRua, na qual foram apresentadas 35 fotografias produzidas pelos moradores de rua, no período de 28 de junho a 5 de julho de 2013 (Figura 6). Para a exposição escolheu-se o Centro de Eventos Culturais da cidade, por ele constituir um local de representação histórica da cidade, de fácil acesso para a população, e por ser parte dos cenários escolhidos pelos participantes da oficina para ser fotografado.

A exposição visou interferir nas preconcepções e preconceitos que a sociedade mantém a respeito da pessoa em situação de rua, bem como dar visibilidade ao potencial criativo das pessoas envolvidas e à condição da pluralidade que as une na dimensão de toda condição humana - mudar o olhar que a sociedade construiu sobre a populaçáo em situação de rua e, ao mesmo tempo, interferir na autoimagem absorvida por essas pessoas a partir dos preconceitos sociais. Para tanto, na inauguração foram mobilizadas pelos autores a Secretaria Municipal de Assistência Social de Ribeirão Preto, a mídia oficial e local, pessoas em situação de rua que frequentavam o CREAS-POP e os terapeutas ocupacionais e estagiários do Curso de Terapia Ocupacional (FMRP-USP).

Para as pessoas em situação de rua usuárias do CREAS-POP, a participação na inauguração da exposição (Figura 7) permitiu que se percebessem 


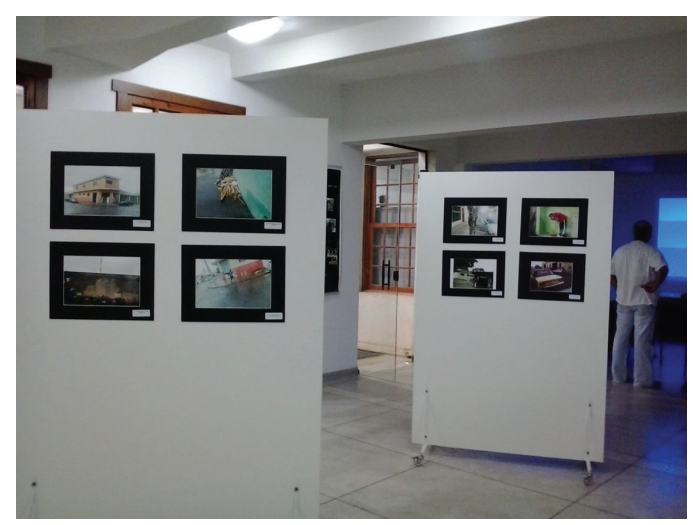

Figura 6. Alguns dos painéis da exposição AndaraRua, no Centro de Eventos Culturais.

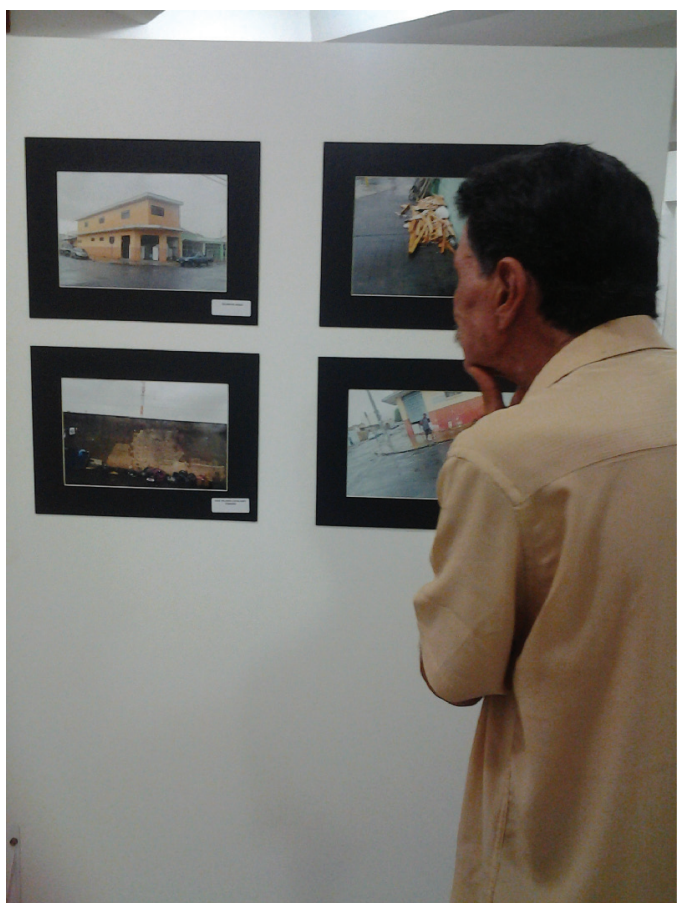

Figura 7. Um dos participantes olha as fotos na inauguração da exposição AndaraRua.

como cidadãos e integrantes da sociedade - a arte e a cultura concretizaram uma forma de elas inserirem-se em dispositivos sociais da cidade e de expressarem seus desejos, sonhos, história pessoal e necessidades.

Para os participantes da Oficina de Fotografia, a exposiçáo de fotos foi o momento em que se concretizou todo o trabalho desenvolvido: a percepçáo de que o material produzido estava sendo valorizado e exposto em um importante centro cultural da cidade fez com que eles se sentissem como sujeitos, cidadãos e integrantes da sociedade capazes de desenvolver atividades socialmente valorizadas.

Muitos visitantes impressionaram-se ao descobrirem quem eram os fotógrafos, considerando-se assim que o objetivo inicial da exposição, de interferir nas preconcepçóes e preconceitos da sociedade, foi atingido. A exposição AndaraRua possibilitou dar visibilidade ao morador de rua e criar um espaço de comunicaçáo com a sociedade, bem como mobilizar o setor político do município para a construção de melhores condiçóes de vida para essa população.

Para a condição da população de rua no município, observou-se que a exposiçáo ensejou um impacto no poder público e nas discussóes sobre o enfrentamento dessa problemática, visto que até o momento discutia-se a mudança do serviço, localizado no centro da cidade, para uma região periférica, no sentido de excluir duplamente a população do convívio da sociedade, que se mostrava incomodada com a presença deles.

Para os estagiários foi possível conhecer o morador de rua e compreender sua condição existencial, envolvendo esse processo revisão de valores e de ideias preconcebidas. Permitiu lidar com as pessoas em situação de rua de forma a entender que a situação na qual se encontram náo advém apenas de suas escolhas pessoais, ao longo da vida, não sendo eles os autoprodutores das circunstâncias em que vivem, mas entendendo que, na realidade, sua condiçáo é uma consequência de construções históricas e sociais, envolvendo aspectos sociais amplos, por viverem em uma conjuntura de vulnerabilidade e desfiliação na qual poucas oportunidades são oferecidas ao segmento social que integraram desde seu nascimento. Foi possível perceber que, no momento atual, essas pessoas necessitam de recursos para reconstruir sua história de vida, de modo a possibilitar um movimento de saída da passividade diante do contexto de exclusão social, proporcionando potências para a sua inserção ativa na sociedade e provocando mudanças, a fim de que trilhem novos caminhos. Esse trabalho concretizou, para os estagiários, o papel do terapeuta ocupacional como articulador social e permitiu que essa função articuladora fosse vivenciada. Ainda, proporcionou algo que, inicialmente, parecia ser um conceito bastante teórico e utópico.

Muitos são os aspectos envolvidos na problemática da população em situação de rua, como a precarização ou rompimento total das relaçóes de trabalho, ruptura dos vínculos familiares e comunitários e o uso intenso de álcool e outras drogas. Consequentemente, há perda do suporte familiar, comunitário e da identidade social de trabalhador. Além disso, a condiçáo de rua insere-se em toda a discussão social que envolve a coletividade frente à necessidade urgentíssima de implementar políticas de enfrentamento e erradicação da pobreza como 
condição imprescindível à democratização da sociedade. Por ser uma situação que se apresenta através de múltiplos significados, aspectos e dimensóes interpretativas, as estratégias de intervenção junto a essa população devem ser pensadas levando-se em conta sujeitos e contextos, sendo necessárias estratégias intersetoriais que envolvam setores da saúde, da assistência social, da educação, cultura, meio ambiente, entre outras. Somente a partir da conscientização da complexidade da problemática das pessoas em situação de rua é que será possível a construção de uma rede intersetorial de atenção.

A problemática das pessoas em situação de rua é complexa, sendo de cunho social, econômico, cultural e político, por esse motivo as iniciativas e estratégias de enfrentamento da vulnerabilidade social devem envolver a formulação intersetorial de políticas públicas, integrando as existentes e elaborando programas que se constituam com base em um conjunto de açôes geradas na interface dos vários setores sociais e esferas de governo. Para tanto, deveria haver uma articulaçáo em rede dos serviços gerados com base em políticas públicas setoriais, como as de saúde, habitação, trabalho e renda, educação e segurança alimentar; Redes Sociais Locais e Movimentos Sociais; demais órgãos do Sistema de Garantia de Direitos; Ministério Público, Defensoria Pública, Centros de Defesa; Sistema de Segurança Pública; Instituiçôes de Ensino; Programas de Instituições Não Governamentais e articulação para acesso à documentação pessoal.

O Encontro sobre População em Situação de Rua, que reuniu gestores municipais, organizaçóes e entidades de assistência social que trabalham com o tema, bem como fóruns e movimentos representativos da população que se encontra em situação de rua, teve como objetivo identificar os desafios estratégicos da construção de uma política pública voltada para esse segmento que seja nacionalmente articulada, em conformidade com os princípios e diretrizes do Sistema Único de Assistência Social (SUAS). Nesse encontro discutiu-se a intersetorialidade, em que se concluiu que mesmo privilegiando essa ou aquela política há a necessidade de interface, reconhecendo que nenhuma delas, sozinha, pode dar conta da situação complexa que condiciona o estar nas ruas. Fica explícito a necessidade de garantir a política pública como direito (BRASIL, 2006).

Sendo assim, as propostas referentes à população em situaçáo de rua deveriam girar em torno da integração, interação, sinergia e comunicação entre os setores envolvidos, para elaboração e implementação de políticas públicas integradas e resolutivas.
Na prática, o que se percebe é que os setores trabalham de forma isolada. A população em situação de rua que normalmente fica à margem das políticas públicas e sociais, a partir da Oficina de Fotografia teve seu trabalho reconhecido e valorizado, tendo ocorrido uma mobilização do poder público para tornar a exposiçâo viável. A presença de representantes da Secretaria Municipal de Assistência Social e da mídia oficial demonstra que a intervenção da Terapia Ocupacional foi um meio eficaz para provocar mudanças no que é oferecido à população em situação de rua e para chamar a atençáo para a necessidade de maiores investimentos e de aporte de recursos nessa área.

\section{Considerações finais}

A problemática da população em situação de rua mostra-se complexa e solicita intervençôes inovadoras que possibilitem a mobilização social no intuito de fomentar um movimento na sociedade para que sejam construídas novas possibilidades de inserção das populaçôes que em decorrência das condiçôes sociais, econômicas e culturais encontram-se excluídas. Compreende-se que o terapeuta ocupacional tem o papel de desenvolver açóes que promovam a mobilização da sociedade e a revisão das políticas e condiçóes existentes no intuito de promover maior participação e inserção das populaçôes em situação de vulnerabilidade.

O recurso da fotografia envolveu um movimento de transformação de valores e paradigmas para usuários, profissionais do serviço, coordenadores da oficina e ampliou-se para a sociedade e o poder público ao concretizar-se na forma de exposição fotográfica. Porém tal mobilização só se torna possível quando o profissional, terapeuta ocupacional, está atento e engajado nas manifestaçôes e transformaçôes sociais e busca por meio de suas açóes promover mudanças na realidade social na qual se insere e com a qual trabalha.

\section{Referências}

ALMEIDA, M. C. et al. Terapia ocupacional e pessoas em situação de rua: criando oportunidades e tensionando fronteiras. Cadernos de Terapia Ocupacional, São Carlos, v. 19, n. 3, p. 351-360, 2011.

BARROS, D. D.; GUIRARDI, M. I. G.; LOPES, R. E. Terapia Ocupacional social. Revista de Terapia Ocupacional da USP, São Paulo, v. 13, n. 2, p. 95-103, 2002.

BARROS, D. D.; LOPES, R. E.; GALHEIGO, S. M. Terapia ocupacional: concepçóes e perspectivas. In: CAVALCANTI, A.; GALVÃO, C. Terapia ocupacional: fundamentação \& prática. Rio de Janeiro: Guanabara Koogan, 2007. p. 347-353. 
BAUER, M. W. Análise de conteúdo clássica: uma revisão. In: BAUER, M. W.; GASKELL, G. (Orgs.). Pesquisa qualitativa com texto, imagem e som: um manual prático. Tradução de Pedrinho A. Guareschi. Petrópolis: Vozes, 2002. p. 189-217.

BRASIL. Ministério do Desenvolvimento Social e Combate à Fome. Relatório do I Encontro Nacional sobre População em Situação de Rua. Brasília, 2006.

BRASIL. Ministério do Desenvolvimento Social e Combate à Fome. Pesquisa nacional sobre população em situação de rua. Brasília, 2008.

BRASIL. Decreto no 7.053, de 23 de dezembro de 2009. Institui a Política Nacional para a População em Situação de Rua e seu Comitê Intersetorial de Acompanhamento e Monitoramento, e dá outras providências. Diário Oficial da República Federativa do Brasil, Poder Executivo, Brasília, DF, 23 dez. 2009.

BRASIL. Decreto no 7179, de 20 de maio de 2010. Institui o Plano Integrado de Enfrentamento ao Crack e outras Drogas, cria o seu Comitê Gestor, e dá outras providências. Diário Oficial da Uniāo, Poder Executivo, Brasília, DF, 21 maio 2010.

BULlA, L. C.; MENDES, J. M. R.; PRATES, J. C. (Org.). As múltiplas formas de exclusão social. Porto Alegre: Federação Internacional de Universidades Católicas; EDIPUCRS, 2004.

COSTA, A. P. M. População em situação de rua: contextualizaçáo e caracterização. Textos \& Contextos, Porto Alegre, v. 4, n. 4, p. 1-15, 2005.

DRUMMOND, A. F. Fundamentos da terapia ocupacional. In: CAVALCANTI, A.; GALVĀO, C. Terapia Ocupacional: fundamentação \& prática. Rio de Janeiro: Guanabara Koogan, 2007. p. 10-17.

GALHEIGO, S. M. Da adaptação psico-social à construção do coletivo: a cidadania enquanto eixo. Revista de Ciências Médicas, Campinas, v. 6, n. 2-3, p. 105-108, 1997.
GHIRARDI, M. I. G. et al. Vida na Rua e Cooperativismo: transitando pela produção de valores. Interface: Comunicação, Saúde e Educação, Botucatu, v. 9, n. 18, p. 601-610, 2005.

LOPES, R. E.; PALMA, A. M.; REIS, T. A. M. A experimentação teórico-pratica do aluno de Terapia Ocupacional no campo social: uma vivência com a população de rua. Revista de Terapia Ocupacional da USP, São Paulo, v. 16, n. 2, p. 54-61, 2005.

MALFITANO, A. P. S. Campos e núcleos de intervenção. Revista de Terapia Ocupacional da USP, São Paulo, v. 16, n. 1, p. 1-8, 2005.

MALFITANO, A. P. S.; MARQUES, A. C. R. A entrevista como método de pesquisa com pessoas em situação de rua: questốes de campo. Cadernos de Terapia Ocupacional, São Carlos, v. 19, n. 3, p. 289-296, 2011.

MATTOS, R. M.; FERREIRA, R. F. Quem vocês pensam que (elas) são? Representações sobre as pessoas em situação de rua. Psicologia \& Sociedade, Porto Alegre, v. 16, n. 2, p. 47-58, 2004. http://dx.doi.org/10.1590/ S0102-71822004000200007

OLIVER, F. C.; BARROS, D. D. Reflexionando sobre desinstitucionalización y terapia ocupacional. Materia Prima: Primera Revista Independiente de Terapia Ocupacional en Argentina, Argentina, v. 4, n. 13, p. 17-20, 1999.

RIBEIRÃO PRETO. Prefeitura Municipal. Serviço Especializado para Pessoas em Situação de Rua. Serviço Especializado em Abordagem Social. Ribeirão Preto, 2011. SAWAIA, B. As artimanhas da exclusão: análise psicossocial e ética da desigualdade social. 7. ed. Petrópolis: Vozes, 2007. SILVA, M. L. L. Trabalho e população em situação de rua no Brasil. São Paulo: Cortez, 2009.

\section{Contribuição dos Autores}

Todos os autores foram responsáveis pela concepção e elaboração do manuscrito, revisão e redação final do texto. 